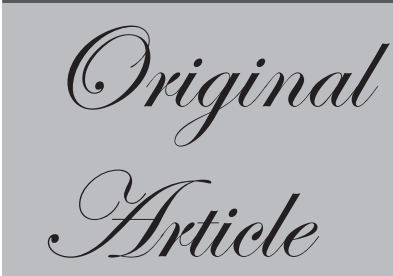

Department of

${ }^{1}$ Surgical Gastroenterology, ${ }^{2}$ Pathology, ${ }^{3}$ General Surgery, ${ }^{4}$ Gastroenterology and ${ }^{6}$ Pathology, Apollo Hospitals, Bhubaneswar - 751012, Odisha, India

Corresponding Author:

Dr. Mohammad Ibrarullah

Email:ibrarullahm60@gmail.com

\section{Cholecystectomy for Asymptomatic Gallstones: Clinicopathological Study}

\author{
Mohammad Ibrarullah ${ }^{1}$, Manas R Baisakh ${ }^{2}$, Ambika \\ Prasad Dash ${ }^{3}$, Asutosh Mohapatra ${ }^{4}$, Sangram Keshari \\ Sahoo $^{1}$, Apurva Agarwal ${ }^{6}$
}

ABSTRACT

Background: Treatment of asymptomatic gallstones is a matter of debate. Aim: The present study was undertaken to find justification for prophylactic cholecystectomy.

Method: The clinical profile, safety of cholecystectomy and extent of histological changes, in patients with asymptomatic gallstones were evaluated.

Result: 150 consecutive patients with incidentally detected gallstones were included in the present study. 122 patients underwent laparoscopic cholecystectomy alone. The procedure was converted to open cholecystectomy in one $(0.8 \%)$. The duration of surgery was less than $1 \mathrm{hr}$ in 96, between 1-2 hrs in 30 and more than two hrs in 24 patients. There was no postoperative death and no major complications. Histology of gallbladder specimen showed features of chronic cholecystitis in all patients. In addition, gastric metaplasia, intestinal metaplasia and dysplasia, considered to be precursors of malignancy, were also noted in significant number of patients. Adenocarcinoma and carcinoma in situ were reported in one patient each $(1.3 \%)$.

Conclusion: Our study has shown that laparoscopic cholecystectomy is technically less demanding and can be safely performed in patients with asymptomatic gallstones. Despite clinically being silent, the stone/s induces inflammatory changes in the gallbladder wall that may predispose to malignancy. A slightly higher incidence of malignancy in the present series may be a reflection of endemicity of the disease. Hence, cholecystectomy should be offered to good risk patients even if the patient has asymptomatic gall stone disease.

KEYWORDS: Cholelithiasis, gallstones, silent, asymptomatic, carcinoma gallbladder. 


\section{Introduction}

The incidence of gallstone (GS) ranges from $4-20 \% .^{1-3}$ Asymptomatic gallstone (AGS) is defined as the presence of GS detected incidentally in patients who do not have any abdominal symptoms or have symptoms that are not thought to be due to gallstones. The diagnosis is made during routine ultrasound for other abdominal conditions oroccasionally by palpation of the gall bladder at operation. ${ }^{4}$ Approximately $80 \%$ of the patients with GS are symptomatic., ${ }^{5,6}$ Progression from asymptomatic to symptomatic disease ranges from $10-25 \%$ over a period of 5-15 years. ${ }^{7}$ Routine use of ultrasonogram for all abdominal symptoms, pregnancy and corporate health check-up programs has led to frequent detection of AGS. Once detected, despite being asymptomatic, it can be a source of constant anxiety and patients seeking treatment is not unusual. Introduction of laparoscopic cholecystectomy has apparently simplified the treatment of GS. However, treatment of AGS is still a matter of considerable debate. A recent Cochrane Database Systematic Review concluded that -" there is no evidence in literature to either recommend or refuse surgery to patients with asymptomatic gallstones". ${ }^{8}$ Some of the accepted indications of cholecystectomy for AGS are - associated polyp $>1 \mathrm{~cm}$, porcelain gallbladder, concomitant abdominal surgery, sickle cell disease, prolonged TPN, patient on chronic immune suppression, patient undergoing bariatric surgery, endemicity of gallbladder cancer. ${ }^{8}$ Of all the stated indications, the one which possibly deserves more attention is the association of gallbladder cancer (GBC) with cholelithiasis. Though the "cause\& effect" relationship can be a matter debate, association of GBC with cholelithiasis is undisputed. In addition, cholecystectomy has been shown to reduce mortality from GBC. ${ }^{9}{ }^{10}$ Prophylactic cholecystectomy has been recommended in many high risk populations like in Chile. ${ }^{9,11,12} \mathrm{GBC}$ is endemic in northern as well as eastern Indian states ${ }^{13,14}$ and the incidence has been reported to be on the rise. ${ }^{14,15}$ Therefore, endemicity of GBC makes a strong case for prophylactic cholecystectomy in this region even if the stones are silent. In a prospective study, all patients undergoing cholecystectomy for silent gallstones in a tertiary care hospital in the eastern part of India were analyzed. The aim was to evaluate the clinical profile, safety of cholecystectomy and extent of histological changes in the gallbladder so as to find justification for prophylactic cholecystectomy.

\section{Material and Methods}

All patients who presented with AGS during May 2008 January 2016 were included in the study. AGS was defined as absence of biliary pain or any GS related complications like obstructive jaundice or pancreatitis. The clinical profile of the patients was recorded. Dyspepsia alone, in the absence of biliary pain, was not considered as symptom of GS. Patients in extremes of age $(<8$ years \& $>$ 80 years), presence of co-morbidity rendering them high surgical / anesthetic risk and pregnancy were not offered surgery and thus excluded from the study. Surgery was performed by the senior author (MI). Laparoscopic cholecystectomy was the procedure of choice unless open surgery was mandated due to associated conditions. The duration of surgery was recorded and categorized into, less than $1 \mathrm{hr}$, between 1-2 hrs and more than $2 \mathrm{hrs}$ to objectify the technical ease / difficulty of cholecystectomy. Postoperative outcome was recorded for up to 4 weeks after cholecystectomy. Histology of the entirecholecystectomy specimen was studied under the supervision of the senior pathologist (MB). Routine (H \& E) staining was used and special stains were used when necessary. Chi square test was used to ascertain statistical significance.

\section{Results}

A total of 150 patients were included in the present study. There were 66 males, 84 females ( $\mathrm{p}=\mathrm{NS}$ ) and the mean age was $42 \mathrm{yr}$ (range 10yr- $76 \mathrm{yr}$ ). The mean duration of presentation since detection of GS was 17 wk (range 3 days$12 \mathrm{yr}$ ). GS in all the patients were detected on ultrasonogram done for routine health check-up in 45, dyspepsia in 38, urinary problem in 17, gynaecologicalproblem in 33, antenatal check-up in four, unexplained vomiting in three, suspected appendicitis, back ache, bleeding per rectum intwo patients each and, nausea, unexplained weight loss, suprapubic lipoma and pyrexia of unknown origin in one patient each. During scanning, the gallbladder was 
critically evaluated for wall thickness-diffuse, focal or irregular, number and location of stone/s and presence of any CBD stone. Diabetes mellitus was the commonest co-morbidity in 37 , followed by hypertension in 36 and hypothyroidism in 12 patients. Bronchial asthma, obesity and ischemic heart disease were present in three patients each. The other co-morbidities were immunosuppressive therapy and chronic renal failure in two patients each and chronic obstructive pulmonary disease, hyperthyroidism, ulcerative colitis and hypopituitarism in one patient each. 26 patients had more than one co-morbidity. 122 patients underwent laparoscopic cholecystectomy alone. The procedure was converted to open cholecystectomy in one $(0.8 \%)$ due to unclear anatomy. In 22 patients, laparoscopic cholecystectomy was combined with another surgical procedure. Six patients underwent open cholecystectomy along with other surgical procedures (Table1). The duration of surgery was less than $1 \mathrm{hr}$ in $96(79 \%$ of all patients who underwent laparoscopic cholecystectomyalone), between 1-2 hrs in 30 and more than two hrs in 24 patients (all the patients who underwent additional procedures). Details of the operative findings

\section{Table 1: Surgical Procedure}

\begin{tabular}{l|l} 
Lap.chole.: & 121 \\
\hline Lap.converted to open chole: & 01 \\
\hline Lap.chole.+Bil TV + GJ: & 01 \\
\hline Lap.chole. + ERC \& CBD stone extraction: & 02 \\
\hline Lap.chole + lap. CBD exploration: & 01 \\
\hline Lap chole + lap assisted GIST excision & 01 \\
\hline Lap.chole. + lap.hysterectomy: & 07 \\
\hline Lap chole + Vag hysterectomy & 01 \\
\hline Lap chole+ lap ovar cyst & 03 \\
\hline Lap.chole. + lap. appendicectomy: & 04 \\
\hline Lap chole + excision of fibrolipoma & 01 \\
\hline Lap chole + TURP & 01 \\
\hline Lap chole + Lap splenectomy & 01 \\
\hline Open chole + nephrectomy: & 02 \\
\hline Open chole. + TV + GJ: & 02 \\
\hline Open chole. + Roux en Y GJ: & 01 \\
\hline Open chole + AR & 01
\end{tabular}

Lap.-laparoscopic, Chole.-cholecystectomy, Bil. TV.- bilateral truncal vagotomy, GJ-gastrojejunostomy, $C B D$ - common bile duct, TURP-Transurethral resection of prostate, AR-Anterior resection, GIST-Gastrointestinal stomal tumor. related to cholecystectomy have been presented in Table 2 . Expectedly, majority of the patients had thin walled GB with normal anatomy. Other significant findings paradoxical to absence of symptoms were, thick walled contracted GB, pericholecystic inflammatory adhesions, stones impacted in Hartman's pouch (Figure 1) and cystic duct, stones in common bile duct (CBD), focal thickening of the GB fundusand mucocele formation. These changes were also noted in the 28 patients who underwent cholecystectomy concomitant with other procedure. There was no perioperative death. The mean hospital stay was 2 days (range 1-9 days). 93 of the 122 $(76 \%)$ patients undergoing laparoscopic cholecystectomy alone had a postoperative stay of one day only. Two patients developed port site sinus. Both responded to antituberculosis treatment based on biopsy of the sinus tract in one and suggestion of grannulomatous hepatitis on CT scan in another. In the immediate postoperative period, one patient developed umbilical port site obstructed hernia resulting from violent cough. The hernia was diagnosed on CT scan and treated by surgery. Sinus bradycardia in another patient in the postoperative period was managed conservatively.

\section{Table 2: Operative Findings}

\begin{tabular}{l|l} 
Thin walled gall bladder \& normal anatomy & 119 \\
\hline Multiple stones & 98 \\
\hline Single stone & 52 \\
\hline Thick walled contracted gallbladder* & 15 \\
\hline Pericholecystic inflammatory adhesions* & 10 \\
\hline Stone impacted in HM pouch* & 03 \\
\hline Stone in the cystic duct & 04 \\
\hline Stone/s in the common bile duct & 03 \\
\hline Wide cystic duct & 04 \\
\hline Right hepatic artery hump & 02 \\
\hline Short cystic duct & 01 \\
\hline Accessary cystic artery & 03 \\
\hline Focal thickening in the gallbladder fundus & 04 \\
\hline Mucoceleformatin & 03 \\
\hline Cholecystohepatic duct & 01 \\
\hline Intrahep GB & 01 \\
\hline Perihepatic adhesions & 01 \\
\hline Hemangioma seg4 & 01 \\
\hline Cirrhotic liver & 01 \\
\hline Perihepatic adhesions & 02
\end{tabular}


Histology of the gall bladder specimen has been presented in Table 3 (Figure 2a-d). Significantly, changes consistent with chronic cholecystitis i.e. various degrees of fibrosis, mucosal hyperplasia, infiltration of chronic inflammatory cells, were present in all patients. Adenocarcinoma and carcinoma in situ were reported in one patient each $(1.3 \%)$

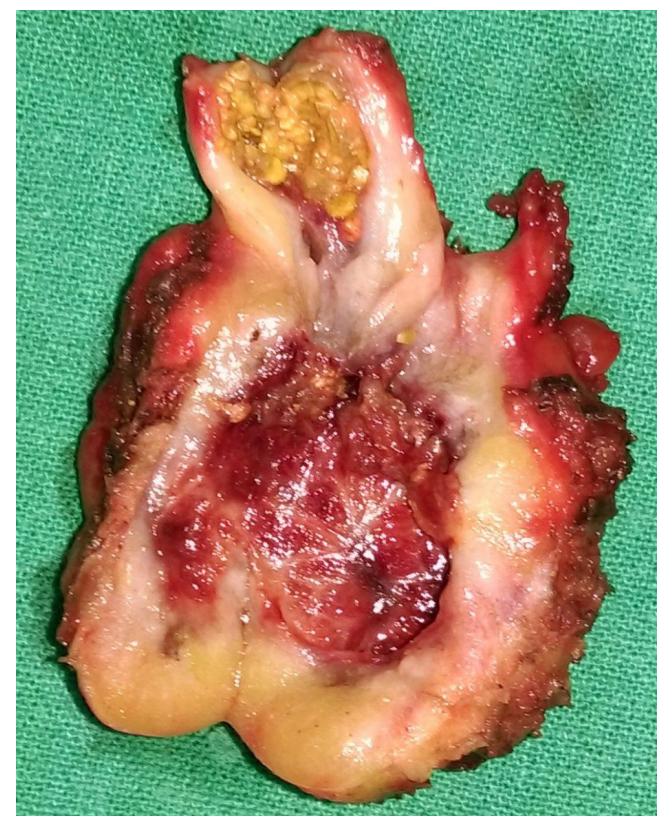

Figure 1: Thick walled contracted gallbladder, stone impacted at Hartman's pouch. Histology of this specimen showed xanthogranulomatous cholecystitis.
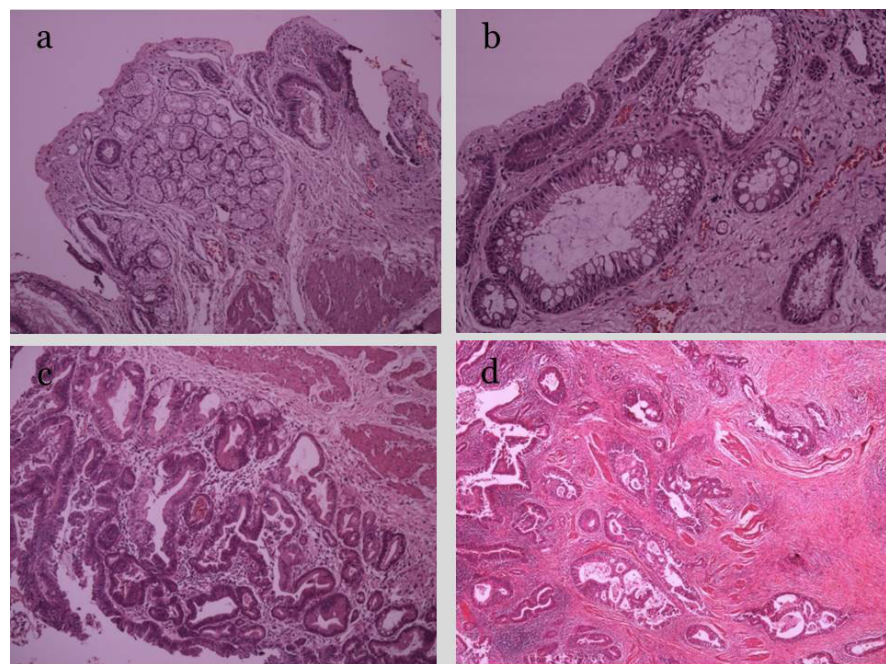

Figure 2: Histology of the gallbladder specimen showing (a) gastric metaplasia, (b) intestinal metaplasia, (c) dysplasia and (d) carcinoma. (H \& E staining).
Table 3: Histology of the cholecystectomy specimen.

\begin{tabular}{l|l} 
Chronic cholecystitis & 150 \\
\hline Cholesterosis & 22 \\
\hline Xanthogranulomatous cholecystitis & 01 \\
\hline Eosinophilic cholecystitis & 01 \\
\hline Follicular cholecystitis & 04 \\
\hline Papillary hyperplasia & 01 \\
\hline Adenomatoid hyperplasia & 01 \\
\hline Intestinal metaplasia & 04 \\
\hline Antral metaplasia & 20 \\
\hline Carcinoma in situ & 01 \\
\hline Adenocarcinoma $\left(\mathrm{T}_{3} \mathrm{~N}_{\mathrm{x}} \mathrm{M}_{\mathrm{x}}\right)$ & 01
\end{tabular}

\section{Discussion}

In the present study majority of the AGS were detected in the course of ultrasound examination for routine health check-up or evaluation of dyspepsia. Contrary to the traditional teaching, it is now well accepted that dyspepsia in the absence of biliary pain should not be attributed to GS. ${ }^{16,17}$ We have, therefore, included this group in the category of AGS. The female preponderance in this study confirms to the standard GS distribution pattern. On the basis of clinical or morphological findings it is not possible to predict the occurrence of symptoms in patients with GS. ${ }^{18}$ In the present study also, patients were asymptomatic despite ongoing inflammation as suggested by thick walled contracted GB or pericholecystic adhesions, stone impacted in Hartman's pouch or cystic duct or even presence of stone in CBD. A higher incidence of female sex and multiple stones in GB as compared to males and single stone respectively, was observed in the present study though the difference was statistically not significant.

Though mortality is not a major concern, morbidity in the form of bile duct injury has been projected as deterrence to offering surgery to patients with AGS. ${ }^{19}$ We, however, feel that the results of cholecystectomy for symptomatic patients should not be extrapolated to cholecystectomy for ASG. Barring exceptions; cholecystectomy for ASG should be technically less demanding. Though 'technical ease or difficulty' is a subjective term, since all the surgery was performed 
by a single surgeon in the present study we have used operating time, conversion rate (from laparoscopic to open cholecystectomy), incidence of bile duct injury and the length of hospital stayforits objectification. In our series in $79 \%$ of patients undergoing laparoscopic cholecystectomy alone, the procedure could be completed in less than one hour. Traditionally the accepted conversion rate reported in literature ranges from 5\%-10\%. ${ }^{20-22}$ In our series only one of the 144 patients $(<1 \%)$ who underwent laparoscopic cholecystectomy had conversion. There was no instance of bile duct injury in our series. This is in contrast to an overall incidence of bile duct injury of $0.2 \%-1 \%$ reported in literature. ${ }^{7,22-24}$ The mean postoperative hospital stay in our series was 2 days of which $76 \%$ of the patients undergoing laparoscopic cholecystectomy alone had a stay of one day. The overall experience in our series is similar to that reported by Coelho etal. In his series of 207 patients, the average operating time was 42 min., with no conversion and no major morbidity and thelength of hospitalization varied from $12 \mathrm{~h}$ to 2 days. ${ }^{25}$

In the present study, histology of gall bladder revealed various degrees of inflammatory changes induced by the 'supposedly' silent stones. Changes consistent with chronic cholecystitis were present in all. Invasive carcinoma and carcinoma in situ were present in one patient each. Inflammation induced mucosal changes like, hyperplasia, metaplasia and dysplasia that may be considered as the chain of events leading to carcinoma, were present in various proportions. Several published studies indicate that presence of gallstone, leading to chronic inflammation, is the initiating event in the development of GBC. It has been postulated that chronic inflammation leads to mucosal lesions such as hyperplasia, metaplasia, dysplasia and finally carcinoma. ${ }^{26}$ Duarte et al showed various degree of mucosal involvement in patients undergoing elective cholecystectomy for gallstonesintestinal metaplasia in $58.1 \%$, hyperplasia in $46.9 \%$, dysplasia in $16 \%$ and carcinoma in situ in $2.5 \% .{ }^{27}$ In a study from New York, the authors reported the incidence of antral type metaplasia, intestinal metaplasia and dysplasia to be $59.5 \%, 9.8 \%$ and $5 \%$ respectively. ${ }^{28}$ In a recent study from India, these precursor lesions were found in various proportion in the cholecystectomy specimen. This study also showed accumulation of loss of heterozygosity at various tumor suppressor genes suggesting a possible causal association of gallstones with GBC. ${ }^{29}$ From the foregoing discussion it is evident that gallstones despite being silent can induce inflammatory changes that can predispose to $\mathrm{GBC}$, thereby making a strong case for prophylactic cholecystectomy. It is, however, not possible to identify the subgroup of patients having advanced inflammatory changes preoperatively. The incidence of malignancy in the present study i.e. $1.3 \%$ is slightly higher than what has been reported with symptomatic gallstones (i.e. $<1 \%$ ). ${ }^{13}$ This may be a reflection of high incidence of gallbladder cancer in this part of the country.

In conclusion, our study has shown that laparoscopic cholecystectomy is technically less demanding andcan be safely performed in patients with AGS with negligible morbidity and no mortality. Despite clinically being silent, the stones induces inflammatory changes in the gallbladder wall that may predispose to malignancy. A slightly higher incidence of malignancy in the present series may be a reflection of endemicity of the disease. Hence, cholecystectomy should be offered to good risk patients even if the stones has notyet become symptomatic.

\section{References}

1. SakorafasHG, Milingos D, Peros G. Asymptomaticcholelithiasis: is cholecystectomy really needed? A critical reappraisal 15 years after the introduction of laparoscopic cholecystectomy. Dig Dis Sci2007; 52:1313-1325.

2. Tandon RK. Prevalence and type of biliary stones in India. World J Gastroenterol 2000; 6: 4-5.

3. Khuroo MS, MahajanR, Zargar SA, Javid G, Sapru S. Prevalence of biliary tract disease in India: a sonographic study in adult population in Kashmir. Gut1989; 30: 201205.

4. WGO practice guideline: asymptomatic gallstone disease. guidelines@worldgastroenterology.org

5. Murshid RK. Asymptomatic gallstones: should we operate?The Saudi Journal of Gastroenterology 2007; 13: 57-69.

6. Kapoor VK. Cholecystectomy in patients with asymptomatic gallstones to prevent gall bladder cancerthe case against. Indian J Gastroenterology 2006; 25: 152- 
154.

7. Behari A, Kapoor VK. Asymptomatic gallstones (AsGS)to treat or not to. Indian J Surg 2012; 74: 4-12.

8. Gurusamy KS, Samraj K. Cholecystectomy for patients with silent gallstones. Cochrane Database of Systematic Reviews 2007; Issue 1. Art. No.: CD006230. DOI: 10.1002/14651858.CD006230.pub2.

9. Lazcano-Ponce EC, Miquel JF, Muñoz N.Epidemiology and molecular pathology of gallbladder cancer. CA Cancer J Clin2001; 51: 349-364.

10. Diehl AK, Beral V. Cholecystectomy and changing mortality from gallbladder cancer. Lancet 1981; 2: 187 189.

11. Puschel K, Sullivan S, Montero J, Thompson B, Diaz A. Cost-effectiveness analysis of a preventive program for gallbladder disease in Chile. Rev Med Chile 2002; 130: 447-459.

12. Randi G, Franceschi S, La Vecchia C. Gallbladder cancer worldwide: geographical distribution and risk factors. Int J Cancer 2006; 118: 1591-1602.

13. Khandelwal M, Khandelwal C. Surgery for advanced gallbladder cancer. Recent Advances in Surgery 2011; 34: 57-71.

14. Sen U, Sankaranarayanan R, Mandal S, Ramanakumar AV, Parkin DM, Siddiqi M. Cancer patterns in eastern India: the first report of the Kolkata cancer registry. Int J Cancer. 2002; 100: 86-91.

15. National Cancer Registry Programme. Consolidated report of the population based cancer registries 1990-1996. Incidence and distribution of cancer. New Delhi: Indian Council of Medical Research. 2001; p.52-53.

16. Kraag N, Thijs C, Knipschild P. Dyspepsia--how noisy are gallstones? A meta-analysis of epidemiologic studies of biliary pain, dyspeptic symptoms, and food intolerance. Scand J Gastroenterol.1995; 30: 411-421.

17. McQuid KR. Dyspepsia. In: Feldman M, Friedman LS, Brandt LJ (ed) Sleisenger and Fordtan's Gastrointestinal and Liver diseases, Philadelphia, Saunders, 2006; pp 121142.

18. Friedman GD, Raviola CA, Fireman B. Prognosis of gallstones with mild or no symptoms: 25 years of follow -up in a health maintenance organization. J ClinEpidemiol 1989; 42: 127-136.

19. SupeA. Asymptomatic gallstones-revisited. Tropical Gastroenterology 2011; 32: 196-203.

20. Livingston EH, Rege RV. A nationwide study of conversion from laparoscopic to open cholecystectomy. Am J Surg. 2004; 188: 205-211.

21. Sakpal SV, Bindra SS, Chamberlain RS. Laparoscopic cholecystectomy conversion rates two decades later. JSLS 2010; 14: 476 -483.

22. Kaushik R, Sharma R, Batra R, Yadav TD, Attri AK, Kaushik SP. Laparoscopic cholecystectomy: an Indian experience of 1233 cases. J LaparoendoscAdvSurg Tech A 20021; 2:21-25

23. Tantia 0 , Jain $M$, Khanna S, Sen B. Iatrogenic biliary injury: 13,305 cholecystectomies experienced by a single surgical team over more than 13 years. SurgEndosc2008; 22:1077-1086

24. Pottakkat B, Vijayahari R, Prakash A. Incidence, pattern and management of bile duct injuries during cholecystectomy: experience from a single centre. Dig Surg2010; 27:375379.

25. Coelho JC, Vizzoto AO, Salvalaggio PR, Tolazzi AR. Laparoscopic cholecystectomy to treat patients with asymptomatic gallstones. Dig Surg. 2000; 17: 344-347.

26. Roa I, Aretxbala X, Araya JC 1. Preneoplastic lesions in gallbladder cancer. J SurgOncol2006; 93: 615-623.

27. Duarte I, Llanos O, Domke H. Metaplasia and precursor lesions of gallbladder carcinoma. Cancer 1993; 72: 18781884.

28. Mukhopadhyay S, Landas SK. Putative precursors of gallbladder dysplasia. Arch Pathol Lab Med 2005; 129: 386-390.

29. Jain K, Mohapatra T, Das P, Mishra MC, Gupta SD, DattaS, et al. Sequential occurrence of preneoplastic lesions and accumulation of loss of heterozygosity in patients with gallbladder stones suggest causal association with gallbladder cancer. Ann Surg2014; 260: 1073-1080. 